\title{
Studying the Pathogenesis of Retinopathy of Prematurity - From Theory to Practice
}

\section{Katargina LA, Chesnokova NB, Balatskaya NV, Beznos OV, Pavlenko TA, Osipova NA* and Panova AYu}

Helmholtz National Medical Research Center of Eye Diseases, Moscow, Russia

*Corresponding Author: Osipova NA, Helmholtz National Medical Research Center of Eye Diseases, Moscow, Russia.
Received: September 11, 2021

Published: October 22, 2021

(C) All rights are reserved by Osipova NA., et al.

\begin{abstract}
The study of the pathogenesis of retinopathy of prematurity (ROP) is the basis for solving clinical problems designed to reduce the level of visual impairment due to ROP.

Purpose: the search for new molecular participants in the development of ROP to build a pathogenetically sustainable basis for improving screening, monitoring, prevention and treatment of the disease.

Material and methods: a comprehensive clinical and experimental study was carried out (763 premature infants of the risk group for ROP were examined in the clinic and 145 Wistar rat pups were included in the experiment), including an assessment of the local and systemic level of 49 cytokines of various biological effects, 4 monoamines and angiotensin-II (AT-II) at different stages of the development of the pathological process.

Results: 8 potential laboratory markers of development and unfavorable course of ROP were identified: content of MCP1 > 95 pg/ml, IGF-II $>140 \mathrm{pg} / \mathrm{ml}$, TGF- $\beta 1<18000 \mathrm{pg} / \mathrm{ml}$ and IGF-I $<24 \mathrm{pg} / \mathrm{mg}$ in blood serum in premature infants before the first signs of the disease and content of VEGF-A > $108 \mathrm{pg} / \mathrm{ml}$, TGF $\beta 2>100 \mathrm{pg} / \mathrm{ml}$, PDGF-BB > $1800 \mathrm{pg} / \mathrm{ml}$, the serotonin $<17.0 \mathrm{pg} / \mathrm{ml}$ in blood serum in premature infants with ROP manifestation. L-DOPA and AT-II indicated its prognostic function in the experiment. All of the listed molecular agents can also be considered as targets for the development of new drugs serving for the prevention and treatment of ROP. Conclusion: a pathogenetically substantiated basis is build for the development of new drug treatments and prevention of ROP, as well as outline ways to improve the ROP screening system.
\end{abstract}

Keywords: Retinopathy of Prematurity; Pathogenesis; Screening; Prevention; Treatment

\section{Abbreviations}

ROP: Retinopathy of Prematurity; AT-II: Angiotensin-II; L-DOPA: L-3,4-Dihydroxyphenylalanine; OIR: Oxygen-Induce Retinopathy; BDNF: Brain-Derived Neurotrophic Factor; EGF: Epidermal Growth Factor; FGF- $\beta$ : Fibroblast Growth Factor-beta; GMSCF: Granulocyte-Macrophage Colony-Stimulating Factor; GRO- $\alpha$ : Growth Related Oncogene-alpha; HGF: Hepatocyte Growth Factor; HIF-1 $\alpha$ :
Hypoxia-Inducible Factor-1 Alpha; IFN: Interferon; IGF: Insulin-like Growth Factor; IL: Interleukin; IP-10: IFN- $\gamma$-Inducible Protein-10; LIF: Leukemia Inhibitory Factor; MIP: Macrophage Inflammatory Protein; MCP-1: Monocyte Chemotactic Protein-1; NGF- $\beta$ : Nerve Growth Factor-beta; PDGF-BB: Platelet-Derived Growth Factor-BB; PEDF: Pigment Epithelium-Derived Factor; PlGF: Placental Growth Factor; SCF: Stem Cell Factor; SDF-1 $\alpha$ : Stromal cell-Derived Factor1alpha; TGF- $\beta$ : Transforming Growth Factor-beta; TNF: Tumor 
Necrosis Factor; VEGF: Vascular Endothelial Growth Factor; PCA: PostConceptual Age.

\section{Introduction}

Retinopathy of prematurity (ROP) remains one of the leading causes of low vision and blindness in children worldwide. A high percentage of unfavorable anatomical and functional outcomes of the disease is due to severe forms of the disease that develop in deeply premature infants with extremely low birth weight. Improving the effectiveness of treatment and prevention of such forms of pathology, as well as improving the screening system are very important tasks designed to reduce the incidence of disability due to ROP. The basis for solving these problems is undoubtedly the study of the pathogenesis of the disease.

Work on the study of the pathogenesis of ROP has been carried out by several scientists from different countries for more than a decade [1-7], but a number of questions still remain open, so this research does not lose its relevance and promise. It is important to note that a holistic work on the study of the mechanisms of ROP development should include an assessment of both local and systemic factors, and since the study of local factors of pathogenesis in the clinic meets natural limitations, experimental studies are of great importance here, allowing to significantly expand the possibilities of analyzing molecular participants in the pathological process in situ.

The purpose of our work was to search for new molecular participants in the development of ROP, to build a pathogenetically substantiated basis for improving screening, monitoring, prevention and treatment of the disease.

\section{Material and Methods}

We carried out a comprehensive clinical and experimental study, including an assessment of the local and systemic level of 49 cytokines of various biological effects, 4 monoamines and one of the most important components of the renin-angiotensin system angiotensin-II (AT-II) at different stages of the development of the pathological process [5,8-14].

Determination of cytokines and monoamines concentration in plasma

The clinical part of the work included examination of 763 premature infants at risk of developing ROP and with developed ROP of various types. The average gestational age at the birth of children was $27 \pm 0.2$ weeks (from 23 to 31 weeks), the average body weight at birth was $1012 \pm 26 \mathrm{~g}$ (from 633 to $1810 \mathrm{~g}$ ). The examination included indirect binocular ophthalmoscopy under conditions of complete mydriasis and determination of the level of cytokines (by multiplex analysis on a flow cytometer) and monoamines (by ELISA) in venous blood samples $(0.5 \mathrm{ml})$. Ophthalmoscopic examination was carried out according to the protocol of ROP screening adopted in Russia with the first examination at the age of 4-6 weeks of life and subsequent monitoring, the protocol of which depended on the type of ROP course [15].

Determination of monoamines concentration in retina in experiment

The experimental part of the study was carried out on the original OIR model (145 Wistar pups were included in the experiment) [16].

Rat pups of experimental (with OIR) and control groups were euthanized on the $7^{\text {th }}, 14^{\text {th }}, 21-23^{\text {rd }}$ and $28^{\text {th }}$ days. All rat pups endured binocular enucleation at the indicated time. The isolated retinas were homogenized in 10 volumes of $0.1 \mathrm{n} \mathrm{HClO} 4$ containing $50 \mathrm{pmol} / \mathrm{ml} \mathrm{3,4-dihydroxybenzylamine} \mathrm{(DHBA)} \mathrm{using} \mathrm{an} \mathrm{ultra-}$ sonic homogenizer (Labsonic M, Sartorius), centrifuged at $2000 \mathrm{~g}$ for 20 minutes, and the resulting supernatant was determined the content of norepinephrine, dopamine and dopamine precursor L3,4 dihydroxyphenylalanine (L-DOPA) using reversed-phase high performance liquid chromatography with electrochemical detection (Amperometric detector LC-4B, Bioanalytical Systems, USA) at a potential of $850 \mathrm{mV}$.

Determination of monoamines concentration in plasma in experiment

Rat pups of experimental (with OIR) and control groups were euthanized on the $14^{\text {th }}, 21^{\text {st }}$, and $30^{\text {th }}$ days and blood was taken from the heart into a test tube with $30 \mu \mathrm{l}$ of $5 \%$ ethylenediaminetetraacetic acid (EDTA) solution (Sigma, USA) and $10 \mu \mathrm{l}$ of $10 \%$ solution sodium metabisulfite (Sigma, USA). Then, the plasma was separated from the shaped elements by centrifugation at $1350 \mathrm{~g}$ for 10 minutes, and 50pmol of DHBA (Sigma, USA) in 0.1 N HCIO4 was added to it. To free it from high molecular weight proteins, the plasma was centrifuged at $16500 \mathrm{~g}$ for 20 minutes. Before the determination of catecholamines, the samples were extracted by 
precipitation on alumina. Further, in the plasma of each sample, the content of L-DOPA, dopamine and norepinephrine was determined by high performance liquid chromatography with electrochemical detection. Separation was carried out on a ReproSil-Pur, ODS-3, $4 \times 100 \mathrm{~mm}$ reverse-phase column with a pore diameter of $3 \mu \mathrm{m}$ (Dr. Maisch GMBH, Germany) at a temperature of $+30^{\circ} \mathrm{C}$ and a mobile phase rate of $1 \mathrm{ml} / \mathrm{min}$ maintained by an LC-liquid chromatograph. 20ADsp (Shimadzu, Japan) at a potential of $850 \mathrm{mV}$.

\section{Determination of AT-II concentration in retina in experiment}

Rat pups of experimental (with OIR) and control groups were euthanized on the $7^{\text {th }}, 14^{\text {th }}$ and $21^{\text {st }}$ days. All rats underwent binocular enucleation, after which the eyeball was opened along the limbus, the cornea and lens were removed along with the remains of the persistent vascular bag and hyaloid artery, and the retina was isolated. Each retina was placed in $200 \mu \mathrm{L}$ of Lysis buffer-3 (Cloud-Clone Corp., USA), homogenized using an UP50H ultrasonic homogenizer (Hielsher, Germany), and centrifuged for $10 \mathrm{~min}$ at $3000 \mathrm{rpm}$. The supernatant was frozen and stored at $-20^{\circ} \mathrm{C}$ until study. In homogenates, the content of AT-II was determined using the ELISA kit for AT-II (rat) (Cloud-Clone corp., USA) and the protein concentration according to Lowry.

Statistical data analysis was carried out in the IBM SPSS Statistics program (version 22) and using the statistical Microsoft package. The studied samples were tested for compliance with the normal distribution using the Shapiro-Wilk test. To determine the statistical significance of the results obtained, the nonparametric Mann-Whitney U-test (U-test) was used. Differences were considered statistically significant at $\mathrm{p}<0.05$. Data are presented as mean \pm standard deviation (mean $\pm \mathrm{SE}$ ).

\section{Results}

In presenting the results of our work in this article, we summarized only on those who showed their pathogenetic properties and have prospects for further study of their prognostic role in the clinic and as a target of drug therapy and prevention.

Of the 49 studied cytokines and growth factors, only 21 were determined in all children: IL-2, IL-18, IL-7, Eotaxin, GRO- $\alpha$, IL8, IP-10, MCP-1, MIP-1 $\beta$, IL- 1RA, LIF, BDNF, VEGF-A, GRO- $\alpha$, HGF, PDGF-BB, SCF, SDF- $1 \alpha$, TGF- $\beta 1$, IGF-I, IGF-II. The quantitative analysis of their the blood serum content of premature infants with different prognosis of ROP development made it possible to identify 7 most promising potential laboratory markers for the development and unfavorable course of ROP: before the onset of the disease, we revealed a higher level of MCP1 and IGF-II and a lower level of TGF $\beta 1$ and IGF-I in children with a subsequent unfavorable course of ROP compared with children who did not develop ROP; in addition, at the initial stages of the development of the disease, the level of VEGF-A, TGF $\beta 2$, PDGFBB was increased in these group of children compared with children with spontaneous regression of the disease [5,8] (Table 1, 2).

\begin{tabular}{|c|c|c|c|c|}
\hline Cytokine & $\begin{array}{l}\text { Children with avascular } \\
\text { zones who have not } \\
\text { developed ROP }\end{array}$ & $\begin{array}{l}\text { Children with avascular } \\
\text { zones with developed } \\
\text { ROP subsequently }\end{array}$ & $\begin{array}{l}\text { Children with active ROP } \\
\text { 1-2 stage (spontaneous } \\
\text { regression subsequently) }\end{array}$ & $\begin{array}{c}\text { Children with active ROP } \\
\text { 1-2 stage (threshold } \\
\text { stage subsequently) }\end{array}$ \\
\hline MCP-1 & $124,87 \pm 30,52^{* *}$ & $251,2 \pm 67,73^{* *}$ & $118,09 \pm 19,06$ & $200,9 \pm 40,95$ \\
\hline TGF $\beta 1$ & $40983,4 \pm 20273,1^{* *}$ & $12667,27 \pm 3065,1^{* *}$ & $11906,25 \pm 1405,1$ & $25269,71 \pm 8357,2$ \\
\hline TGF $\beta 2$ & $315,92 \pm 113,2$ & $206,79 \pm 122,4$ & $35,65 \pm 28,8^{*}$ & $163,32 \pm 39,6^{*}$ \\
\hline VEGF-A & $195,2 \pm 77,2$ & $134,4 \pm 23,8$ & $88,5 \pm 10,9^{*}$ & $175,3 \pm 37,6^{*}$ \\
\hline PDGFBB & $3230,4 \pm 814,6$ & $2467,1 \pm 646,1$ & $1395,4 \pm 243,3^{* *}$ & $3417,3 \pm 1131,4^{* *}$ \\
\hline
\end{tabular}

Table 1: Average content of cytokines and growth factors in blood plasma in children with different course of $\mathrm{pH}(\mathrm{pg} / \mathrm{ml})$.

* Differences are reliable according to Mann-Whitney; ** differences at the level of the Student's trend.

The use of a set of statistical methods for data processing allowed us to designate the "critical" values of the concentration of these factors for prognostic purposes: namely, the content of
MCP1> $95 \mathrm{pg} / \mathrm{ml}$, IGF-II $>140 \mathrm{pg} / \mathrm{ml}, \mathrm{TGF} \beta 1<18000 \mathrm{pg} / \mathrm{ml}$ and IGF-I $<24 \mathrm{pg} / \mathrm{mg}$ in blood serum of premature infants before the onset of the first signs of the disease, as well as levels of VEGF-A> 


\begin{tabular}{|l|c|c|c|}
\hline \multirow{2}{*}{ Cytokine } & $\begin{array}{c}\text { Children without } \\
\text { ROP }\end{array}$ & $\begin{array}{c}\text { Children with } \\
\text { ROP II type }\end{array}$ & $\begin{array}{c}\text { Children with } \\
\text { ROP I type }\end{array}$ \\
\cline { 2 - 4 } & $\begin{array}{c}\text { Average value, } \\
\text { range }\end{array}$ & $\begin{array}{c}\text { Average value, } \\
\text { range }\end{array}$ & $\begin{array}{c}\text { Average value, } \\
\text { range }\end{array}$ \\
\hline \multirow{2}{*}{ IGF-I } & 27,7 & 26,2 & 19,3 \\
IGF-II & $(12,03-38,91)$ & $(13,95-47,94)$ & $(7,74-33,44)$ \\
\hline & 108,7 & 128,8 & 167,6 \\
$(81,9-122,08)$ & $(79,47-223,66)$ & $(79,52-271,74)$ \\
\hline
\end{tabular}

Table 2: Average values of the concentration of insulin-like growth factors in the blood serum of children of three clinical groups at the time of the first ophthalmoscopic examination (pg/ml).

$108 \mathrm{pg} / \mathrm{ml}, \mathrm{TGF} \beta 2>100 \mathrm{pg} / \mathrm{ml}, \mathrm{PDGF}-\mathrm{BB}>1800 \mathrm{pg} / \mathrm{ml}$ with ROP manifestation allow classify them as a high-risk group for severe ROP $[5,8]$.
In the experimental part of the work, data was obtained on the pathogenetic role of dopamine, L-DOPA, and norepinephrine in the development of ROP in situ and systemically [9-12]. In this article, we present more predictively significant results of the study of their systemic level in the experiment and clinic. On the $14^{\text {th }}$ day, i.e. during the induction of pathological vascularization in experimental ROP in our model of the disease [16], a significant decrease in the level of L-DOPA in blood plasma was revealed in the experimental group of rat pups compared to the control group [14]. The content of norepinephrine and dopamine did not differ between the groups (Table 3).

In clinic, dopamine was determined in $44.4 \%$ of the samples, serotonin and norepinephrine in $100 \%$ of the samples. There were no significant differences in dopamine content in children of different groups. Serotonin levels were significantly reduced in children with ROP compared with children without ROP at 32-35 weeks of postconceptual age (PCA) (Figure 1) [8]. The level of norepineph-

\begin{tabular}{|l|c|c|c|c|c|c|}
\hline \multirow{2}{*}{$\begin{array}{l}\text { Day of } \\
\text { experiment }\end{array}$} & \multicolumn{2}{|c|}{ Value of dopamine } & \multicolumn{2}{c|}{ Value of L-DOPA } & \multicolumn{2}{c|}{ Value of norepinephrine } \\
\cline { 2 - 7 } & $\begin{array}{c}\text { Experimental } \\
\text { group }\end{array}$ & $\begin{array}{c}\text { Control } \\
\text { group }\end{array}$ & Experimental group & $\begin{array}{c}\text { Control } \\
\text { group }\end{array}$ & $\begin{array}{c}\text { Experimental } \\
\text { group }\end{array}$ & $\begin{array}{c}\text { Control } \\
\text { group }\end{array}$ \\
\hline 14 & $0,23 \pm 0,13$ & $0,26 \pm 0,18$ & $0,31 \pm, 04^{*}$ & $0,42 \pm 0,08$ & $3,03 \pm 1,54$ & $3,67 \pm 1,73$ \\
\hline 21 & $0,15 \pm 0,06$ & $0,18 \pm 0,05$ & $0,87 \pm 0,29 *$ & $1,53 \pm 0,61$ & $3,39 \pm 1,92$ & $3,64 \pm 1,22$ \\
\hline 30 & $0,09 \pm 0,02$ & $0,09 \pm 0,03$ & $0,33 \pm 0,198$ & $0,21 \pm 0,08$ & $2,83 \pm 0,58$ & $3,42 \pm 1,72$ \\
\hline
\end{tabular}

Table 3: The content of catecholamines in the blood plasma of the experimental and control groups (pmol/g).

$$
\text { * - Differences are significant }(\mathrm{p}<0.05) \text { compared to control. }
$$

rine did not differ between the groups of children with and without ROP, however, there was a tendency to an increase in its concentration $(p=0.06)$ in the group of children with ROP at 36-39 weeks of PCA (i.e., with the progression of the disease) (Figure 2) [8].

Statistical processing of the results allowed us to conclude that the low serotonin content $(<17.0 \mathrm{pg} / \mathrm{ml})$ in the blood serum of premature infants at 32-35 weeks of PCA can serve as another laboratory criterion for the development of ROP. Also, in children with the initial stages of ROP, an increase in the concentration of norepinephrine during dynamic observation can serve as a marker of the progression of the disease [8].

With regard to AT-II in the experiment, we obtained data that at the time which corresponded to the presence of avascular areas of the retina, its retinal level in rat pups with OIR was statistically sig-

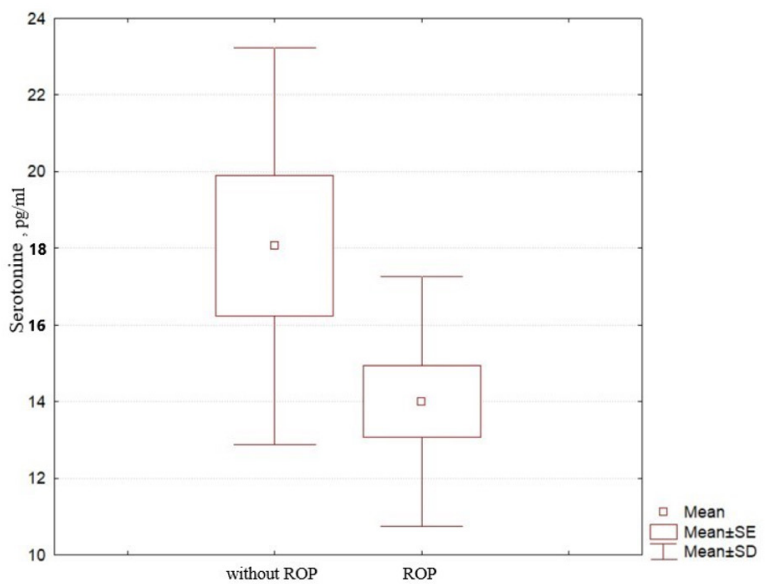

Figure 1: Plasma serotonin content $(\mathrm{pg} / \mathrm{ml})$ in children with and without ROP up to 35 weeks of PCA. 


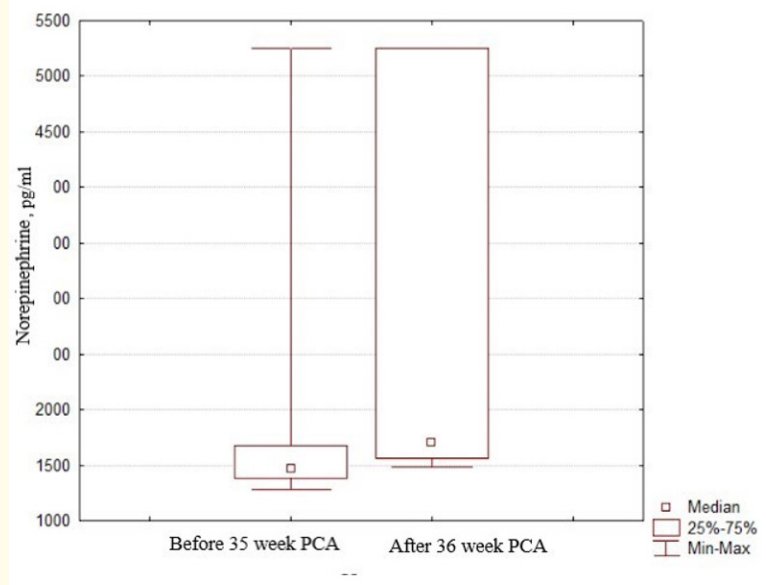

Figure 2: Plasma Norepinephrine content $(\mathrm{pg} / \mathrm{ml})$ in children with ROP.

nificantly higher than in rat pups of the control group, which may indicate a pro-angiogenic role of this participant in the induction of pathological neovascularization in OIR, as well as a possible prognostic role before the onset of the disease [13].

\section{Discussion}

As has been shown in a number of studies, pathological retinal angiogenesis in ROP is a consequence of an imbalance of pro-angiogenic and anti-angiogenic factors [5].

Our analysis of the content of cytokines of various biological effects in the blood plasma of premature infants at different periods of observation confirmed already studied role of VEGF-A and IGF-I in the development of ROP, and also revealed a number of factors, previously little known in the aspect of ROP pathogenesis. These factors include the growth factors IGF-II, MCP-1, PDGF-BB, TGF- $\beta 1$ and $-\beta 2$.

The role of IGF-II in the regulation of angiogenesis has been studied recently relative to ROP. There is evidence of the participation of this growth factor in the development and progression of a number of pediatric oncopathology as one of the inducers of neovascularization. In one of the recent works, its pro-angiogenic properties were shown in the model of oxygen-induced retinopathy in mice - it was revealed that the peptide synthesized on the basis of IGF-II acted as an active inhibitor of angiogenesis, which scientists explained by partial competitive binding to receptors of insulin-like growth factors [17]. Our data also indicate its proangiogenic properties in the pathogenesis of ROP.

The role of the cytokine MCP-1 in the development of various vasoproliferative ophthalmic pathologies is being studied quite actively. An increase in the level of MCP-1 in the vitreous body of patients with proliferative diabetic retinopathy has been revealed [18]. In terms of the pathogenesis of ROP, it was noted that premature babies who subsequently developed the disease had a higher content of MCP-1 in umbilical cord blood compared to premature babies without ROP and full-term infants [19]. Moreover, among premature infants with a birth weight of less than $1000 \mathrm{~g}$, those who needed oxygen therapy for more than 6 hours had higher MCP-1 values in blood taken on day 3 of therapy than those who received oxygen during less time [20]. It has been shown that MCP-1 is involved in the recruitment of macrophages and microglial cells during the ischemic phase of ROP [21,22]. The mechanism of influence of MCP1 on angiogenesis is associated with its stimulation of the expression of HIF1 $\alpha$ and VEGF-A [23]. Our work also confirmed its pro-angiogenic properties.

PDGF-BB, a growth factor belonging to the family of platelet growth factors, is a mitogen for glial cells and cells of mesenchymal origin, including vascular pericytes [24]. An increase in PDGF-BB expression was found in the development of proliferative retinopathy, which was accompanied by the proliferation of astrocytes, pericytes, and endothelial cells [25]. Also, an increase in the systemic level of PDGF-BB accompanied the development of neovascular AMD [26]. The proangiogenic properties of PDGF-BB are also proved by the fact that its inhibition can increase the effectiveness of anti-VEGF therapy in various models of retinal neovascularization [27]. Blocking PDGF-BB receptors also leads to suppression of tumor angiogenesis [28,29]. Our data indicate the participation of PDGF-BB in the regulation of pathological angiogenesis in ROP as its activator.

The data on the role of TGF- $\beta 1$ in angiogenesis and pathogenesis of ROP are contradictory. A decrease in TGF- $\beta 1$ was detected in experimental ROP in mice at an early stage [30], and information about its possible unidirectional nature of action with VEGF-A [31] suggests that a lack of TGF- $\beta 1$ and VEGF-A at certain times can cause retardation of the growth of blood vessels and lead in the fu- 
ture to a more severe course of ROP. Our data on the role of TGF- $\beta 1$ in the pathogenesis of ROP may indicate its antiangiogenic properties and are consistent with the results of the study by Sood et al., In which a higher level of TGF- $\beta 1$ was detected in children without ROP compared with children with ROP. moreover, the minimum values were determined in children with an unfavorable course of ROP [32]. The mechanisms of TGF- $\beta 1$ involvement in the processes of impaired retinal angiogenesis in ROP are not fully understood.

TGF- $\beta 2$ is considered by a number of authors as a factor in the development of connective tissue proliferation. The stimulating role of TGF- $\beta 2$ in the development of fibrotic changes in AMD under hypoxic conditions was revealed, and it was also shown that the level of TGF- $\beta 2$ in the vitreous space was directly proportional to the severity of proliferative vitreoretinopathy [33]. The revealed changes in the level of TGF- $\beta 2$ indicate its possible participation in the pathogenesis of ROP as a profibrovasoproliferative factor.

It is also necessary to pay special attention to our results obtained with respect to monoamines. Serotonin levels were significantly reduced in children with ROP compared with children without ROP at 32-35 weeks of PCA, which indicates its antiangiogenic properties and is consistent with literature data on the ability of serotonin to suppress VEGF-A synthesis [34]. In addition, serotonin is a precursor of melatonin, which, due to its antiangiogenic and antioxidant properties, is capable of inhibiting pathological angiogenesis in OIR [35]. Also, in children with ROP, a tendency to an increase in the content of norepinephrine was revealed as the disease progressed, which indicates its pro-angiogenic properties and requires further study on a larger sample. The experiment obtained extremely interesting data regarding the precursor of dopamine L-DOPA, indicating its antiangiogenic properties in the development of pathology [9-11]. Moreover, a low systemic level of L-DOPA can be considered as a prognostic sign of the development of extraretinal vasoproliferation in OIR, which is the basis for planning clinical trials in order to determine the prognostic value of the L-DOPA level in the blood serum of premature infants as a potential laboratory screening criterion ROP [14].

Of all the components of the renin-angiotensin system, our attention in terms of the pathogenesis of ROP was attracted by the effector peptide AT-II, since in a number of studies its pro-angiogenic properties were found - its ability to stimulate the proliferation of endothelial and smooth muscle cells, migration of pericytes and hypertrophy of smooth muscle cells was shown [36]. VEGF-A is considered as the main possible mediator of its angiogenic properties [37]. The indicated properties of this peptide were confirmed in our work. Moreover, the obtained data are potentially of great practical importance for use in the clinic as a prognostic factor for the development of ROP, the assessment of its concentration in the blood serum require further study of the content of this biologically active substance at the systemic level in the experiment and clinic.

It is important to note that all the studied molecules, whose potential prognostic value was identified, can also be considered as targets for the development of new drugs for the prevention and treatment of ROP - the development of receptor agonists or synthetic analogs of substances, the lack of which was identified on stages of induction of a pathological process, as well as receptor blockers or "traps" for substances found in relative excess.

\section{Conclusion}

The results of the carried out complex clinical and experimental work on the study of the pathogenesis of ROP make it possible to build a pathogenetically substantiated basis for the development of new palliative methods for the treatment and prevention of ROP, as well as outline ways to improve the ROP screening system.

It is planned to continue work to clarify the mechanisms of the identified phenomena, expand the range of laboratory criteria for the development of ROP and assess the possibility of introducing the results into clinical practice.

\section{Acknowledgments}

This study was supported by state assignment on the topic of R\&D (number state registration AAAA-A18-118032390091-7).

\section{Competing Interests}

Authors declare to have no competing interest.

\section{Autor Contribution}

Katargina L.A. - concept and design of the study, scientific editing, approval of the final version of the article;

Chesnokova N.B. - head of biochemical studies;

Balatskaya N.V. - head of immunological studies; 
Beznos 0.V. - biochemical research;

Pavlenko T.A. -biochemical research;

Osipova N.A. - obtaining biological material, writing of text, design of bibliography, responsibility for the integrity of all parts of the article;

Panova A.Yu. - obtaining biological material, performed the statistical analysis.

\section{Bibliography}

1. Cao JH., et al. "Colorado Retinopathy of Prematurity model: a multi-institutional validation study". Journal of AAPOS 20.3 (2016): 220-225.

2. Biniwale M., et al. "Early postnatal weight gain as a predictor for the development of retinopathy of prematurity". Journal of Maternal-Fetal and Neonatal Medicine 32.3 (2019): 429-433.

3. Pivodic A., et al. "Individual Risk Prediction for Sight-Threatening Retinopathy of Prematurity Using Birth Characteristics". JAMA Ophthalmology 138.1 (2019): 1-9.

4. Kim SJ., et al. "Identification of candidate genes and pathways in retinopathy of prematurity by whole exome sequencing of preterm infants enriched in phenotypic extremes". Scientific Report 11 (2021): 4966.

5. Katargina LA., et al. "The role of the systemic disbalance of serum cytokine levels in pathogenesis of retinopathy of prematurity". Rossijskaya Pediatricheskaya Ophthlmologija 4 (2015): 16-20.

6. Chen J., et al. "Retinopathy of prematurity". Angiogenesis 10.2 (2007): 133-140.

7. Hartnett ME. "Studies on the Pathogenesis of Avascular Retina and Neovasculatization into the Vitreous in Peripheral Severe Retinopathy of Prematurity (An American Ophthalmological Society Thesis)". Transactions of the American Ophthalmological Society 108 (2010): 96-119.

8. Panova AYu. "The role of the factors of pathological angiogenesis in pathogenesis of retinopathy of prematurity". Clinicoexperimental study: autoreferat dissertacii kandidata medicinskikh nauk. - Moskow (2021): 21.
9. Katargina LA., et al. "The role of catecholamines in the development of pathological retina neovascularization in an experimental model of retinopathy of prematurity in rats". Doklady Akademii nauk 489.3 (2019): 313-317.

10. Katargina LA., et al. "Studying the pathogenic role of catecholamines in the development of retinopathy of prematurity on an experimental model of the disease". Russian Ophthalmological Journal 12.4 (2019): 64-69.

11. Katargina LA., et al. "Angiogenic properties of catecholamines from the viewpoint of the pathogenesis of retinopathy of prematurity". Russian Ophthalmological Journal 11.4 (2018): 4954.

12. Katargina LA., et al. "The role of monoamines in the regulation of angiogenesis and the prospects for their use in treatment of retinopathy of prematurity". Rossijskaya Pediatricheskaya Ophthlmologija 13.2 (2018): 76-80.

13. Katargina LA., et al. "Angiotensin-II as a trigger factor in the development of retinopathy of prematurity". Oftal'mologija 17.4 (2020): 746-751.

14. Katargina LA., et al. "Prognostic value estimation of monoamins systemic level in retinopathy of prematurity in experiment". Sovremennye Tehnologii v Medicine 13.3 (2021): 41-46.

15. Federal clinical guidelines (National protocol). "Diagnostics, monitoring and treatment of the active phase of retinopathy of prematurity". Rossijskaya Pediatricheskaya Ophthlmologija 1 (2015): 54-60.

16. Katargina LA., et al. "Pathomorphological features of the development of experimental retinopathy of prematurity". Mezhdunarodnyj zhurnal prikladnyh i fundamental'nyh issledovanii 3.2 (2017): 190-194.

17. Zheng Y., et al. "Novel peptide derived from IGF-2 displays antiangiogenic activity in vitro and inhibits retinal angiogenesis in a model of oxygen-induced retinopathy". Clinical and Experimental Ophthalmology 48.9 (2020): 1261-1275.

18. Eastlake K., et al. "Müller glia as an important source of cytokines and inflammatory factors present in the gliotic retina during proliferative vitreoretinopathy". Glia 64.4 (2016): 495506. 
19. Yu H., et al. "Serum concentrations of cytokines in infants with retinopathy of prematurity". APMIS 122.9 (2014): 818-823.

20. Natarajan G., et al. "Circulating $\beta$ chemokine and MMP 9 as markers of oxidative injury in extremely low birth weight infants". Pediatric Research 67.1 (2010): 77-82.

21. Yoshida S., et al. "Role of MCP-1 and MIP-1 $\alpha$ in retinal neovascularization during postischemic inflammation in a mouse model of retinal neovascularization". Journal of Leukocyte Biology 73.1 (2003): 137-144.

22. Yoshida S., et al. "Induction of IL-8, MCP-1, and bFGF by TNF- $\alpha$ in retinal glial cells: implications for retinal neovascularization during post-ischemic inflammation". Graefe's Archive for Clinical and Experimental Ophthalmology 242.5 (2004): 409-413.

23. Hong KH., et al. "Monocyte chemoattractant protein-1-induced angiogenesis is mediated by vascular endothelial growth factor-A". Blood 105 (2005): 1405-1407.

24. Andrae J., et al. "Role of platelet-derived growth factors in physiology and medicine". Genes and Development 22.10 (2008): 1276-1312.

25. Seo MS., et al. "Photoreceptor-specific expression of plateletderived growth factor-B results in traction retinal detachment". The American Journal of Pathology 157.3 (2000): 995-1005.

26. Zehetner C., et al. "Systemic upregulation of PDGF-B in patients with neovascular AMD”. Investigative Ophthalmology and Visual Science 55.1 (2014): 337-344.

27. Jo N., et al. "Inhibition of platelet-derived growth factor B signaling enhances the efficacy of anti-vascular endothelial growth factor therapy in multiple models of ocular neovascularization". The American Journal of Pathology 168.6 (2006): 2036-2053.

28. Lin B., et al. "Anlotinib inhibits angiogenesis via suppressing the activation of VEGFR2, PDGFR $\beta$ and FGFR1". Gene 654 (2018): 77-86.

29. Tsioumpekou M., et al. "Specific targeting of PDGFR $\beta$ in the stroma inhibits growth and angiogenesis in tumors with high PDGF-BB expression". Theranostics 10.3 (2020): 1122.
30. Li H., et al. "Role of TGF-Beta1/SMAD2/3 Pathway in Retinal Outer Deep Vascular Plexus and Photoreceptor Damage in Rat 50/10 0xygen-Induced Retinopathy". BioMed Research International 2019 (2019).

31. Nagineni CN., et al. "Transforming growth factor- $\beta$ induces expression of vascular endothelial growth factor in human retinal pigment epithelial cells: Involvement of mitogen-activated protein kinases". Journal of Cellular Physiology 197.3 (2003): 453-462.

32. Sood BG., et al. "Perinatal systemic inflammatory response syndrome and retinopathy of prematurity". Pediatric Research 67.4 (2010): 394-400.

33. Saika S. "TGF $\beta$ pathobiology in the eye". Laboratory Investigation 86.2 (2006): 106-115.

34. Cerezo AB., et al. "Anti-VEGF signalling mechanism in HUVECs by melatonin, serotonin, hydroxytyrosol and other bioactive compounds". Nutrients 11.10 (2019): 2421.

35. Xu Y., et al. "Melatonin attenuated retinal neovascularization and neuroglial dysfunction by inhibition of HIF- $1 \alpha$-VEGF pathway in oxygen-induced retinopathy mice". Journal of Pineal Research 64.4 (2018): e12473.

36. Sarlos S., et al. "Retinal angiogenesis is mediated by an interaction between the angiotensin type 2 receptor, VEGF, and angiopoietin". American Journal of Pathology 163.3 (2003): 879-887.

37. Tamarat R., et al. "Angiotensin II angiogenic effect in vivo involves vascular endothelial growth factor- and inflammationrelated pathways". Laboratory Investigation 82 (2002): 747756.

\section{Volume 5 Issue 11 November 2021}

(C) All rights are reserved by Osipova NA., et al. 